\title{
MicroRNA-186 affects the proliferation of tumor cells via yes-associated protein 1 in the occurrence and development of pancreatic cancer
}

\author{
QINGHUI NIU ${ }^{1}$, XIAOYU LI $^{2}$, DI XIA ${ }^{3}$, YUEPING JIANG ${ }^{1}$, ZIBIN TIAN $^{2}$, CHENG BIAN $^{1}$, \\ CUIPING ZHANG ${ }^{2}$, PEI LIU ${ }^{1}$, FENGJUAN ZHANG ${ }^{1}$, YULING YANG ${ }^{1}$ and GUANGLAN WANG ${ }^{1}$ \\ Departments of ${ }^{1}$ Infection, ${ }^{2}$ Gastroenterology and ${ }^{3}$ Emergency, Affiliated Hospital \\ of Qingdao University, Qingdao, Shandong 266003, P.R. China
}

Received May 3, 2016; Accepted March 31, 2017

DOI: $10.3892 /$ etm.2017.4770

\begin{abstract}
The present study aimed to determine the expression of microRNA (miRNA or miR)-186 in tumor tissues and peripheral blood of patients with pancreatic cancer (PC), as well as its mechanism of regulation. A total of 65 patients with PC who underwent surgery between June 2013 and October 2015 were included. In addition, 59 healthy subjects were recruited as controls. Reverse transcription-quantitative polymerase chain reaction was used to measure the expression of mRNA and miRNA. Western blotting and enzyme-linked immunosorbent assay were used to determine protein expression. Bioinformatics was employed for the prediction of the target gene of miR-186, whereas dual luciferase reporter assay was performed to identify whether miR-186 directly bound to YAP1 mRNA. Human pulmonary aortic endothelial cells (HPACs) were transfected with ago-miR-186. YAP1 expression in HPACs was silenced by siRNA. MTT assay was used to evaluate the viability of HPACs. YAP1 mRNA and protein expression levels were elevated in PC. In addition, expression levels of miR-186 in $\mathrm{PC}$ were downregulated. miR-186 regulated the expression of YAP1 by binding with the 3'-untranslated region of YAP1. Elevated expression of miR-186 inhibited the proliferation of HPACs by downregulating the expression of YAP1. Decreased expression of YAP1 by siRNA reduced the viability of HPACs. The present study demonstrates that YAP1 is upregulated in the tumor tissues and blood of PC patients, and this may be associated with the downregulation of miR-186. In addition, miR-186 may affect the occurrence and development of PC by controlling the proliferation of PC cells via YAP1.
\end{abstract}

Correspondence to: Dr Zibin Tian, Department of Gastroenterology, Affiliated Hospital of Qingdao University, 16 Jiangsu Road, Qingdao, Shandong 266003, P.R. China E-mail: uip789@126.com

Key words: pancreatic cancer, microRNA-186, yes-associated protein 1

\section{Introduction}

As a type of common digestive system tumor, pancreatic cancer (PC) has particularly high morbidity and mortality rates. $\mathrm{PC}$ has the eighth highest incidence rate among all tumor types in the USA (1) and, according to its mortality rates, PC ranks fourth among all cancer types in the USA (2). It has also been reported that the incidence of PC in China is increasing year by year (3). Studies of PC can be divided into the steps of diagnosis, treatment, and prognosis. At present, there is no publicly accepted screening method for the early detection of PC. Surgical treatment is the only method that can cure PC. However, postoperative 5-year survival rates are only $15-25 \%$, despite radical resection (4). In order to provide necessary clinical information, a diagnosis model has been established using the clinical indices that predict the prognosis of PC, in which biological markers have important roles (5-7). Various biological markers related to PC have been identified $(8,9)$. Previous investigations have demonstrated that upregulated expression of YAP1 has an important role in the occurrence and development of PC, and the pathogenesis of the majority of PC cases is accompanied by gradually increased expression of YAP1 $(10,11)$. With the progression of studies on microRNA (miRNA or miR), researchers have discovered that the upregulation of miRNA expression is able to inhibit the expression of YAP1, leading to the inhibition of the formation, proliferation and metastasis of tumor cells $(12,13)$. However, the regulatory effect of miR-186 on YAP1 in PC has rarely been reported in basic and clinical researches. The present study aimed to measure YAP1 mRNA and protein expression levels in tumor tissues and blood from PC patients, and investigate the regulatory effect of miR-186 on YAP1 expression.

\section{Materials and methods}

Patients. A total of 65 patients with PC who underwent surgery between June 2013 and October 2015 were included in the present study. In addition, 59 healthy subjects were recruited as controls. PC group included 38 men and 27 women aged between 48 and 81 years (median age, 61.6 years). Control group included 33 men and 26 women aged between 45 and 88 years 
(median age, 63.5 years). All PC patients were experiencing the onset of PC for the first time and had no history of using hormones, Chinese medicine, or chemoradiotherapy. Tumor tissues and tumor-adjacent noncancerous tissues were resected and collected from all PC patients prior to being frozen at $-80^{\circ} \mathrm{C}$ within $2 \mathrm{~h}$. Fasting peripheral blood samples were collected from all patients and healthy subjects in the morning, and stored at $-20^{\circ} \mathrm{C}$. All procedures were approved by the Ethics Committee of Qingdao University (Qingdao, China). Written informed consent was obtained from all subjects or their families.

Reverse transcription-quantitative polymerase chain reaction (RT-qPCR). Tumor and tumor-adjacent noncancerous issues $(100 \mathrm{mg})$ were ground into powder using liquid nitrogen prior to the addition of $1 \mathrm{ml}$ TRIzol (10606ES60; Yeasen, Shanghai, China) for lysis. Following lysis, total RNA was extracted using the phenol chloroform method. RNA purity was determined by A260/A280 using ultraviolet spectrophotometry (Nanodrop ND1000; Thermo Fisher Scientific, Inc., Waltham, MA, USA). cDNA was obtained by RT from $1 \mu \mathrm{g}$ RNA using a TIANScript II cDNA kit (KR107; Tiangen Biotech Co., Ltd., Beijing, China) and stored at $-20^{\circ} \mathrm{C}$. Primers for YAP1 were as follows: 5'-CTTCGGCTTTATGGCTAC CT-3' (upstream) and 5'-AAGGTCAGATGGTGGTTG TTC-3' (downstream). Primers for GAPDH were as follows: 5'-CGGAGTCAACGGATTTGGTCGTAT-3' (upstream) and 5'-AGCCTTCTCCATGGTGGTGAAGAC-3' (downstream). The RT-qPCR reaction system $(25 \mu \mathrm{l})$ contained $10 \mu \mathrm{l}$ RT-qPCR-Mix, $0.5 \mu 1$ upstream primer, $0.5 \mu 1$ downstream

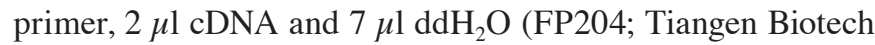
Co., Ltd.). The thermal cycling PCR protocol was as follows: Initial denaturation at $95^{\circ} \mathrm{C}$ for $30 \mathrm{sec}$, followed by 40 cycles of denaturation at $95^{\circ} \mathrm{C}$ for $5 \mathrm{sec}$ and annealing at $60^{\circ} \mathrm{C}$ for $30 \mathrm{sec}$ (iQ5; Bio-Rad Laboratories, Inc., Hercules, CA, USA). The $2^{-\Delta \Delta \mathrm{Cq}}$ method was used to calculate the relative expression of YAP1 against GAPDH (14). For RT-qPCR to measure miR-186, similar protocols were used. Primers for miR-186 were as follows: 5'-CCCGATAAAGCTAGATAACC3-3' (upstream) and 5'-CAGTGCGTGTCGTGGAGT-3' (downstream). Primers for U6 were as follows: 5'-GCTTCGGCAGCACATATACTAAAAT-3' (upstream) and 5'-CGCTTCACGAATTTGCGTGTCAT-3' (downstream). PCR conditions included initial denaturation at $95^{\circ} \mathrm{C}$ for $5 \mathrm{~min}$, followed by 40 cycles of denaturation at $95^{\circ} \mathrm{C}$ for $10 \mathrm{sec}$, annealing at $60^{\circ} \mathrm{C}$ for $20 \mathrm{sec}$, and elongation at $72^{\circ} \mathrm{C}$ for $20 \mathrm{sec}$ (iQ5; Bio-Rad Laboratories, Inc.). The $2^{-\Delta \Delta \mathrm{Cq}}$ method was used to calculate the relative expression of miR-186 using U6 as an internal reference.

Enzyme-linked immunosorbent assay (ELISA). Blood samples were centrifuged at $1,200 \mathrm{x} g$ at room temperature for $10 \mathrm{~min}$ for the separation of serum. Levels of YAP1 were measured using an ELISA kit (KA3582; Amyjet Scientific Inc., Wuhan, China). The procedure was performed according to the manufacturer's manual. Absorbance at $450 \mathrm{~nm}$ was measured using a microplate reader (Bio-Rad Laboratories, Inc.) within 15 min after the reactions were terminated.

Bioinformatics. Bioinformatics prediction is the basis for functional studies of miRNAs. Target gene prediction software, including miRanda (microma.org/rnicroma/home .do), TargetScan (targetscan.org), PiTa (genie.weizmann .ac.il/pubs/mir07/mir07_data.html), RNAhybrid (bibiserv.techfak.uni-bielefeld.de/rnahybrid/) and PICTA (pictar.mdc-berlin.de/), was used to predict whether miR-186 was one of the genes that could regulate YAP1. miR-186 was predicted to be one of the genes that could regulate YAP1, which informed the remainder of the study.

Dual luciferase reporter assay. According to the bioinformatics results, wild-type (WT) and mutant seed regions of miR-186 in the 3'-untranslated region (UTR) of YAP1 gene were chemically synthesized in vitro, supplemented with SpeI and HindIII restriction sites (Sangon Biotech, Co., Ltd., Shanghai, China), and cloned into pMIR-REPORT luciferase reporter plasmids (Thermo Fisher Scientific, Inc.). Plasmids $(0.8 \mu \mathrm{g})$ with WT or mutant 3'-UTR DNA sequences were co-transfected with ago-miR-186 (100 nM) into HEK293T cells. Following cultivation for $24 \mathrm{~h}$, the cells were lysed using a dual luciferase reporter assay kit (catalogue no. E1910; Promega Corp., Madison, WI, USA) according to the manufacturer's manual, and fluorescence intensity was measured using a GloMax 20/20 luminometer (Promega Corp.). Using Renilla fluorescence activity as an internal reference, the fluorescence values of each group of cells were measured.

Cell transfection. Human pulmonary aortic endothelial cells (HPACs) in log-phase growth were seeded into 24-well plates $\left(3 \times 10^{5}\right) 24 \mathrm{~h}$ prior to transfection, and cultured in antibiotic-free F12/Dulbecco's modified Eagle medium supplemented with $10 \%$ fetal bovine serum (GE Healthcare, Chicago, IL, USA). When cells reached $70 \%$ confluency, $1.25 \mu$ l plasmids containing siRNA and ago-miR-186 and $1 \mu$ l Lipofectamine 2000 (Thermo Fisher Scientific, Inc.) were added into two individual vials containing $50 \mu \mathrm{l}$ OptiMemi medium, respectively. After $5 \mathrm{~min}$, the liquids in the two vials were mixed before being left to stand for another $20 \mathrm{~min}$. Subsequently, the mixture was added to the cells and incubated for $6 \mathrm{~h}$. Following this, the medium was replaced with fresh medium and the cells were cultured at $37^{\circ} \mathrm{C}$ and $5 \% \mathrm{CO}_{2}$ for $48 \mathrm{~h}$ before use.

Western blotting. HPACs were trypsinized and collected prior to treatment with precooled radio-immunoprecipitation assay lysis buffer (600 $\mu \mathrm{l}$; $50 \mathrm{mM}$ Tris-base, $1 \mathrm{mM}$ EDTA, $150 \mathrm{mM}$ $\mathrm{NaCl}, 0.1 \%$ sodium dodecyl sulfate, $1 \%$ TritonX-100 and $1 \%$ sodium deoxycholate; Beyotime Institute of Biotechnology, Shanghai, China). Following lysis for $50 \mathrm{~min}$ on ice, the mixture was centrifuged at $12,000 \mathrm{x} \mathrm{g}\left(4^{\circ} \mathrm{C}\right)$ for $5 \mathrm{~min}$. The supernatant was used to determine protein concentration with a bicinchoninic acid protein concentration determination kit (RTP7102; Real-Times Biotechnology Co., Ltd., Beijing, China). Protein samples $(20 \mu \mathrm{g})$ were subsequently mixed with equal volumes of $2 \mathrm{X}$ SDS loading buffer before denaturation in boiling water bath for $5 \mathrm{~min}$. Following this, the samples were separated by $10 \%$ SDS-PAGE at $100 \mathrm{~V}$. Resolved proteins were transferred to polyvinylidene difluoride membranes on ice $(100 \mathrm{~V} ; 2 \mathrm{~h})$ and blocked with $5 \%$ skimmed milk at room temperature for $1 \mathrm{~h}$. Then, the membranes were incubated with rabbit anti-human YAP1 polyclonal primary antibody $(1: 1,000 ;$ ab39361) and rabbit anti-human $\beta$-actin primary 

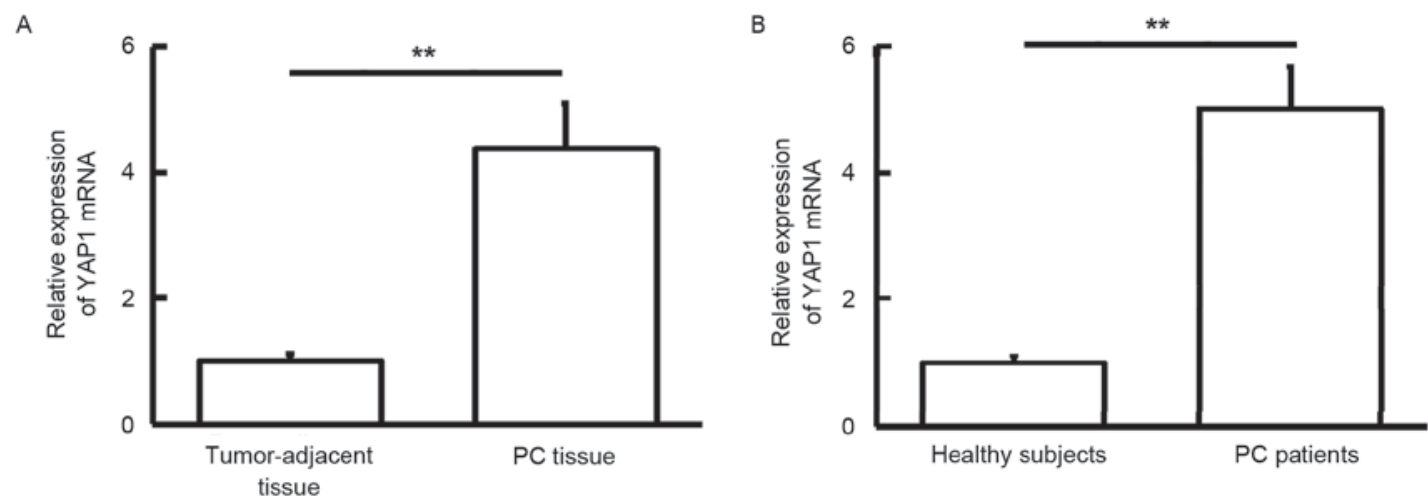

Figure 1. Expression of YAP1 mRNA in (A) tumor tissues and tumor-adjacent tissues from PC patients, and (B) peripheral blood from healthy subjects and PC patients. ${ }^{* *} \mathrm{P}<0.01$. YAP1, yes-associated protein 1 ; PC, pancreatic cancer.

antibody (1:5,000; ab129348; both Abcam, Cambridge, UK) at $4^{\circ} \mathrm{C}$ overnight. Following extensive washing with phosphate-buffered saline with Tween $20(3 \times 15 \mathrm{~min})$, the membranes were incubated with goat anti-rabbit horseradish peroxidase-conjugated secondary antibody (1:3,000; ab6721; Abcam) for $1 \mathrm{~h}$ at room temperature before washing with phosphate-buffered saline with Tween 20 (3x15 min). Then, the membrane was developed using an enhanced chemiluminescence detection kit (Sigma-Aldrich; Merck KGaA, Darmstadt, Germany) for imaging. Image lab software (version 3.0; Bio-Rad Laboratories, Inc.) was used to acquire and analyze imaging signals. The relative content of YAP1 protein was expressed as a YAP1/ $\beta$-actin ratio.

MTT assay. HPACs were seeded into a 96-well plate in triplicate at a density of $2 \times 10^{3}$ cells/well. Empty wells were set in 96-well plate as blank control, while cell-free wells with reagent were used as negative control. The solvent to dissolve the crystals was dimethyl sulphoxide. For incubation for 24,48 and $72 \mathrm{~h}, 5 \mathrm{~g} / \mathrm{l}$ MTT (20 $\mu \mathrm{l}$ per well) was added (JRDC000003; JRDUN Biotechnology, Shanghai, China). Cells were subsequently incubated at $37^{\circ} \mathrm{C}$ for $4 \mathrm{~h}$, after which $150 \mu \mathrm{l}$ dimethyl sulfoxide was added and the cells were incubated for another $15 \mathrm{~min}$. Absorbance of each well was measured at $490 \mathrm{~nm}$ with a microplate reader (Bio-Rad Laboratories, Inc.). A cell viability curve was subsequently plotted.

Statistical analysis. Results were analyzed using SPSS v18.0 statistical software (SPSS Inc., Chicago, IL, USA). All data were expressed as means \pm standard deviation. Data were tested for normality. Multiple sets of measurement data were analyzed using one-way analysis of variance. If homogeneity of variance was detected, data were analyzed using Least Significant Difference and Student-Newman-Keuls methods; whereas Tamhane's T2 or Dunnett's T3 methods were employed during heterogeneity of variance. $\mathrm{P}<0.05$ was considered to indicate a statistically significant difference.

\section{Results}

YAP1 mRNA expression is elevated in PC. To measure YAP1 mRNA expression levels in tissues and blood samples, RT-qPCR was used. The findings showed that YAP1 mRNA levels in PC tissue were significantly higher than those in tumor-adjacent tissue $(\mathrm{P}<0.01$; Fig. 1A). In addition, YAP1 mRNA levels in peripheral blood samples from PC patients were significantly elevated compared with those of healthy subjects $(\mathrm{P}<0.01$; Fig. 1B). These result suggest that YAP1 mRNA expression is elevated in PC.

YAP1 protein expression is increased in $P C$. To measure YAP1 protein expression levels in tissues and blood samples, western blotting and ELISA were performed. Western blotting data showed that YAP1 protein levels in PC tissue were significantly higher than those in tumor-adjacent tissue $(\mathrm{P}<0.05$; Fig. 2A), whereas ELISA demonstrated that YAP1 protein levels in the peripheral blood of PC patients were significantly increased compared with those of healthy subjects $(\mathrm{P}<0.05$; Fig. 2B). These results indicate that, consistent with YAP1 mRNA expression, YAP1 protein expression is also increased in PC.

Expression of miR-186 is downregulated in PC. To determine the expression levels of miR-186 in tissues and blood samples, RT-qPCR was performed. The findings showed that miR-186 levels in PC tissue were significantly lower than those in tumor-adjacent tissue ( $\mathrm{P}<0.01$; Fig. 3A). In addition, miR-186 levels in the peripheral blood of PC patients were significantly reduced when compared with those of healthy subjects $(\mathrm{P}<0.05$; Fig. 3B). These results suggest that miR-186 expression is downregulated in PC.

miR-186 regulates the expression of YAP1 by binding with the 3'-UTR of YAPI. To determine whether miR-186 was able to target YAP1, a dual luciferase reporter assay was performed. The findings showed that transfection with ago-miR-186 and pMIR-REPORT in the WT group resulted in significantly reduced fluorescence intensity, as compared with the negative control $(\mathrm{P}<0.05)$. Fluorescence intensity in the mutant group was not significantly different from that of the negative control (Fig. 4). These results indicate that miR-186 regulates the expression of YAP1 by binding with the 3'-UTR of YAP1.

Elevated expression of miR-186 inhibits the viability of HPACs by downregulating the expression of YAPI. To determine the effect of miR-186 on the viability of HPACs, the cells were 
A

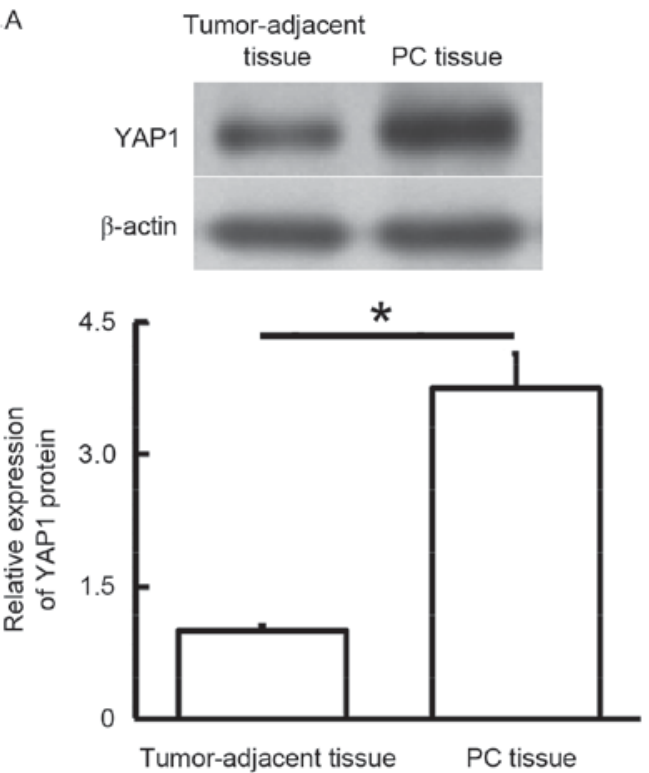

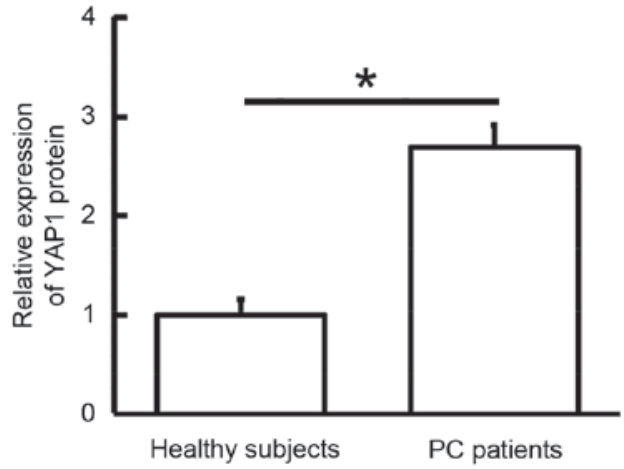

Figure 2. Expression of YAP1 protein in (A) tumor tissues and tumor-adjacent tissues from PC patients, and (B) peripheral blood from healthy subjects and PC patients. ${ }^{*}<<0.05$. YAP1, yes-associated protein 1; PC, pancreatic cancer.

A

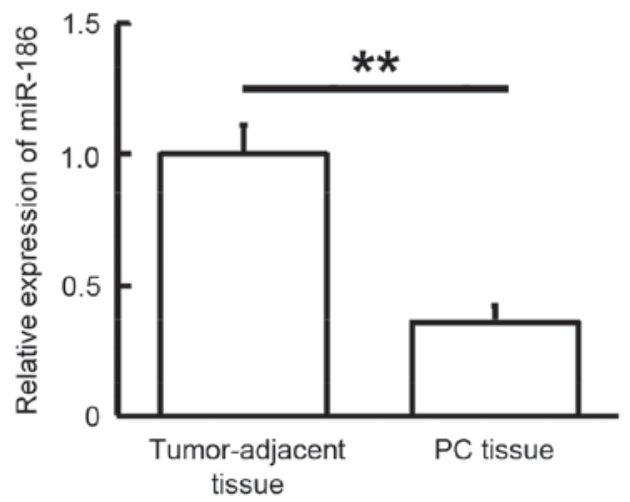

B

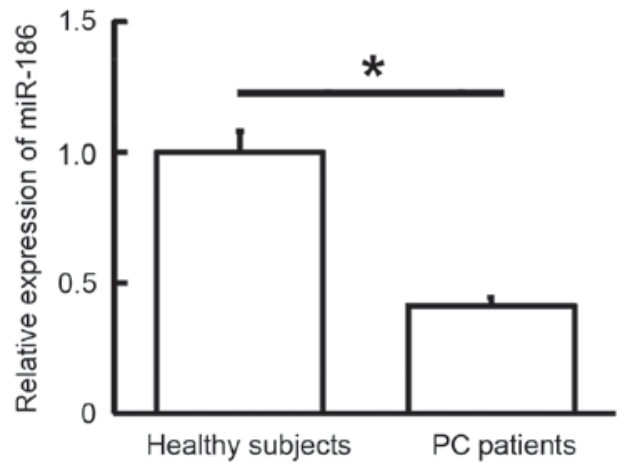

Figure 3. Expression of miR-186 in (A) tumor tissues and tumor-adjacent tissues from PC patients, and (B) peripheral blood from healthy subjects and PC patients. ${ }^{*}<0.05$ and ${ }^{* * *} \mathrm{P}<0.01$. YAP1, yes-associated protein 1; PC, pancreatic cancer.

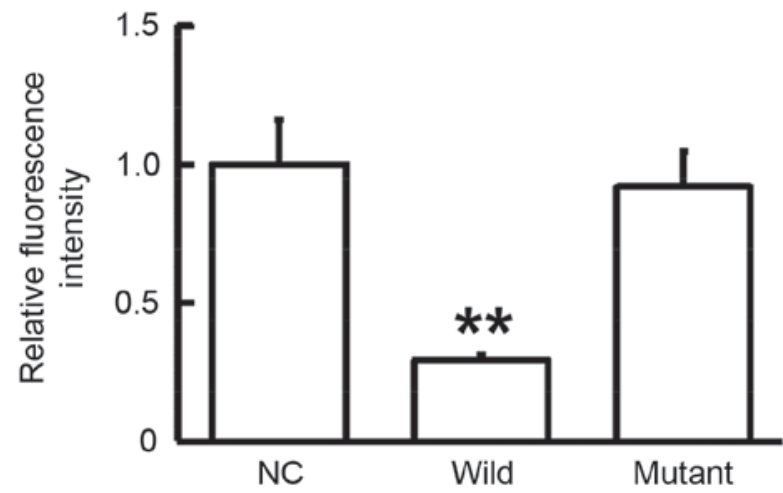

Figure 4. Interaction between miR-186 and YAP1 was detected by dual luciferase reporter assay. Plasmids $(0.8 \mu \mathrm{g})$ with WT or mutant 3'-UTR DNA sequences were co-transfected with ago-miR-186 (100 nM) into HEK293T cells. Following cultivation for $24 \mathrm{~h}$, the cells were lysed using dual luciferase reporter assay kit and fluorescence intensity was measured. Using Renilla fluorescence activity as internal reference, the fluorescence values of each group of cells were measured. ${ }^{* *} \mathrm{P}<0.01$ vs. NC. WT, wild-type; UTR, untranslated region; NC, negative control; YAP1, yes-associated protein 1. transfected with ago-miR-186. RT-qPCR data showed that the expression of miR-186 was increased and the expression of YAP1 mRNA was decreased in HPACs after transfection with ago-miR-186 ( $\mathrm{P}<0.05$; Fig. 5A and B). In addition, MTT assay showed that the viability of HPACs was inhibited after transfection with ago-miR-186 at $72 \mathrm{~h}(\mathrm{P}<0.05$; Fig. 5C). These results suggest that elevated expression of miR-186 inhibits the proliferation of HPACs by downregulating the expression of YAP1.

Decreased expression of YAPI by siRNA inhibits the proliferation of HPACs. To elucidate the effect of YAP1 on the viability of HPACs, cells were transfected with siRNA of YAP1. RT-qPCR showed that expression of YAP1 mRNA was significantly reduced after transfection with YAP1 siRNA ( $\mathrm{P}<0.01$; Fig. 6A). Consistently, western blotting data showed that YAP1 protein expression in HPACs was also decreased after transfection with YAP1 siRNA $(\mathrm{P}<0.01$; Fig. 6B). MTT assay demonstrated that the viability of HPACs 

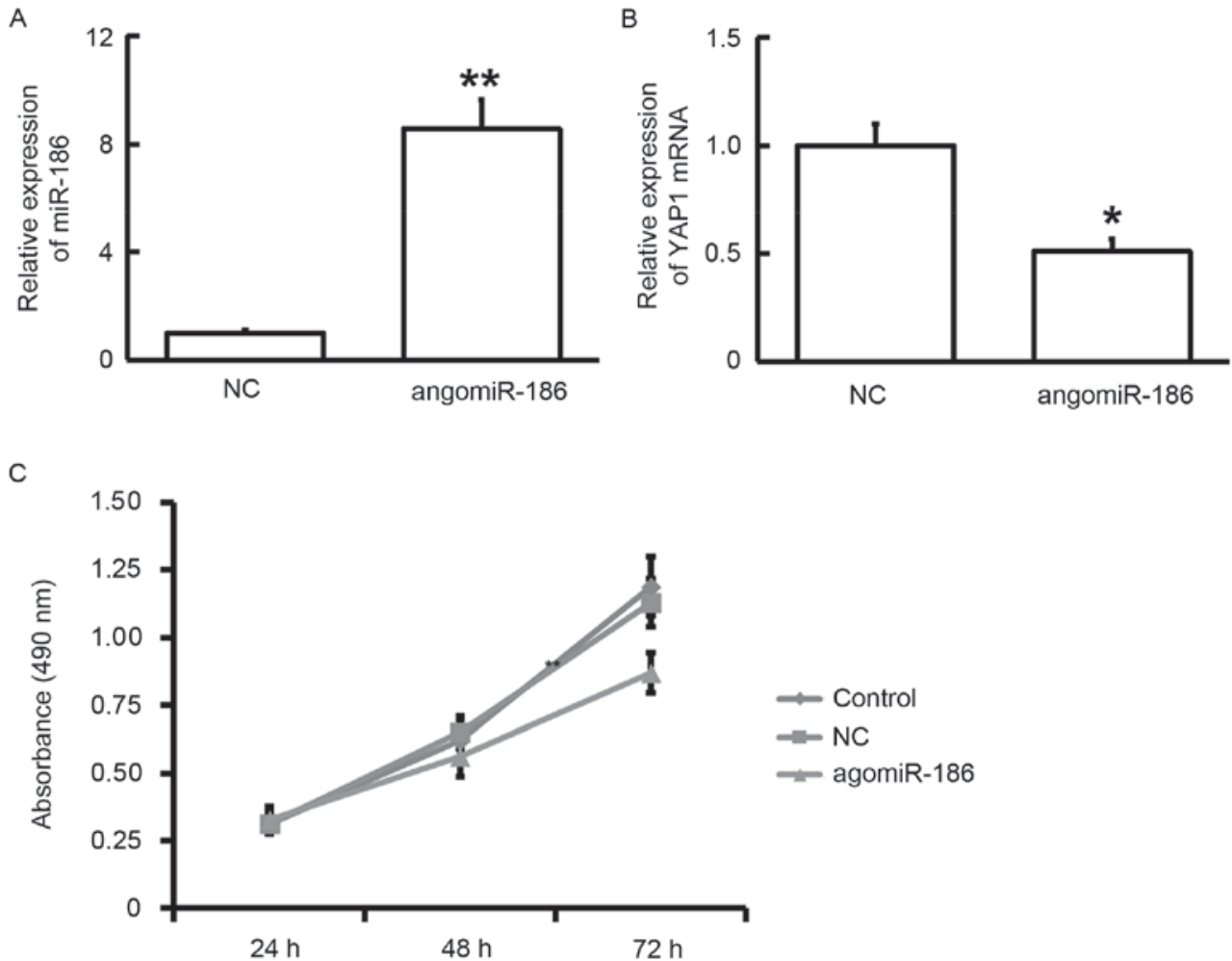

Figure 5. Effect of ago-miR-186 transfection on HPACs. (A) Expression of miR-186 after transfection with ago-miR-186. (B) Expression of YAP1 mRNA after transfection with ago-miR-186. (C) Viability of HPACs after transfection with ago-miR-186, as determined by MTT assay. ${ }^{*} \mathrm{P}<0.05$ and ${ }^{* * *} \mathrm{P}<0.01$ vs. NC. HPACs, human pulmonary aortic endothelial cells; NC, negative control.
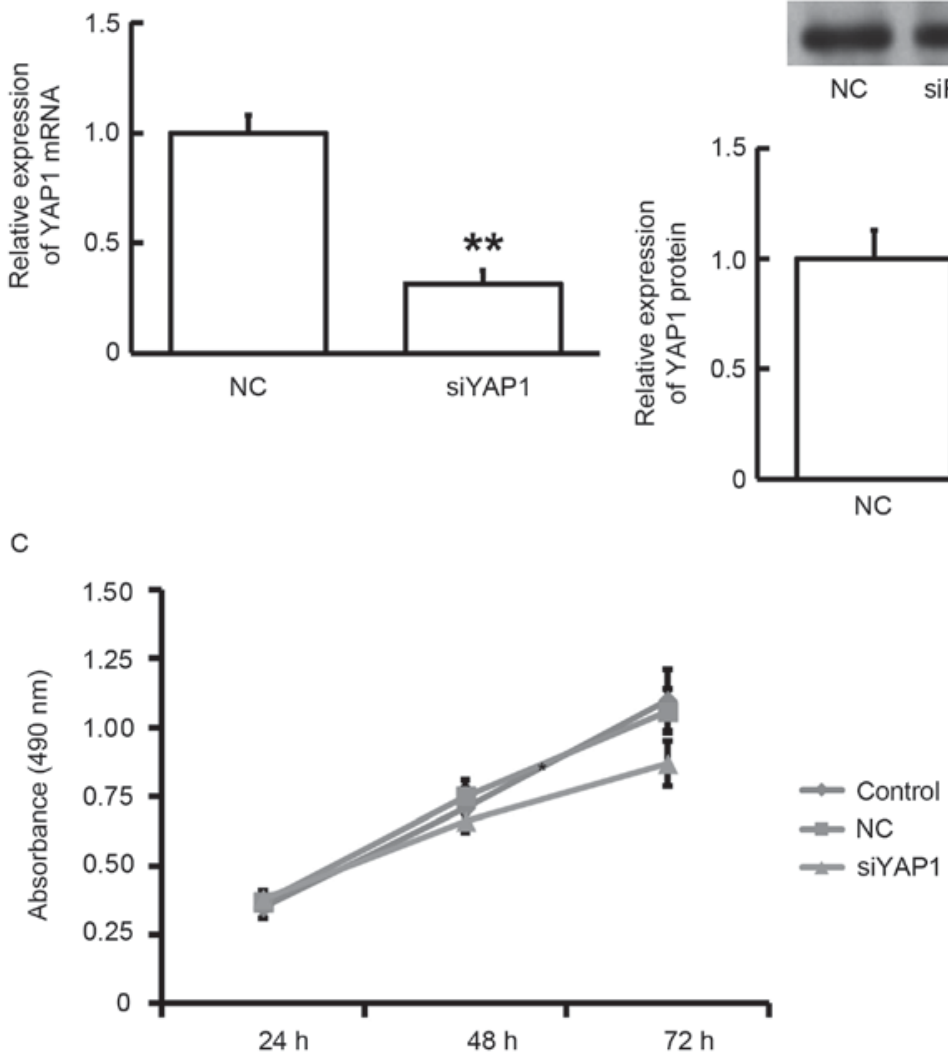

Figure 6. Effect of YAP1 expression on HPACs. (A) Expression of YAP1 mRNA after transfection with YAP1 siRNA. (B) Expression of YAP1 protein after transfection with YAP1 siRNA. (C) Viability of HPACs after transfection with siRNA of YAP1 as determined by MTT assay. "* P $<0.01$ vs. NC. YAP1, yes-associated protein 1; HPACs, human pulmonary aortic endothelial cells; siRNA, short interfering RNA; NC, negative control. 
was significantly reduced in HPACs transfected with YAP1 siRNA at $72 \mathrm{~h}(\mathrm{P}<0.05$; Fig. $6 \mathrm{C})$. These results indicate that the siRNA-induced decrease in the expression of YAP1 inhibited the proliferation of HPACs.

\section{Discussion}

PC occurrence and development is a complex process that involves multiple genes and steps. With the development of biological treatment, it is important to elucidate the pathogenesis of PC and to elucidate novel treatment targets. In the present study, we determined the expression levels of YAP1 mRNA and protein in tumor tissues and peripheral blood from PC patients, as well as the levels of miR-186 upstream of YAP1. Biological functions of miR-186 and YAP1 were investigated using cell experiments. YAP1 protein $(65 \mathrm{kDa})$ is one of the two main effectors of the Hippo tumor suppressor pathway, and its gene is located at human chromosome llq22 (15). It has previously been reported that YAP1 is a potent oncogene that is amplified in various types of human cancer (16), participating in the proliferation, survival, maintenance of stem cell phenotype, invasion, and metastasis of tumor cells $(17,18)$. Several studies have shown that YAP1 levels in tissues are able to predict the prognosis of patients with ovarian cancer $(19,20)$, endometrial cancer (21), gastric cancer, colon cancer (22), breast cancer (23) and head and neck squamous cell carcinoma (24). In the present study, the expression levels of YAP1 mRNA and protein in PC tissues were elevated, suggesting that changes in YAP1 expression may be associated with the occurrence of PC, and abnormal expression of YAP1 may be important for the occurrence of PC. Organs with rich blood flow often become distant metastatic targets of PC cells via blood circulation, and a serious consequence of this is metastasis to other parts of the body $(19,20)$. Therefore, YAP1 detected in the blood may indirectly reflect the malignancy and metastatic status of PC cells.

miRNA molecules have been found to inhibit the translation of YAP1 (25). Using bioinformatics, we predicted upstream genes that may regulate YAP1, and found that miR-186 is closely related with YAP1. Studies have shown that miR-186 may become a novel target for the prediction, diagnosis and treatment of tumors. Zhang et al (26) discovered that miR-186 is a predictor of the diagnosis of pancreatic ductal adenocarcinoma, and it affects the proliferation and invasion of tumor cells. Lee et al (27) demonstrated that upregulation of miR-186 is closely related with the inhibited proliferation of human lung fibroblasts. Sun et al (28) showed that miR-186 regulates the formation of fibroblasts that are associated with tumors. Cui et al (29) reported that miR-186 targets Rock1 and inhibits the proliferation and migration of non-small-cell lung carcinoma cells. Consistent with these findings, the results of the present study demonstrated that miR-186 expression levels in tumor tissues and peripheral blood from PC patients were significantly reduced, whereas YAP1 expression in these samples was demonstrated to be significantly increased. Therefore, we propose that the downregulation of miR-186 is one of the reasons for the upregulation of YAP1, finally leading to changes in the biological functions of PC cells. In order to clarify the underlying molecular mechanism, we transfected HPACs using ago-miR-186 and the findings indicated that elevated expression of miR-186 reduced the proliferation of HPACs. Furthermore, RT-qPCR also showed that increased miR-186 expression levels induce the downregulation of YAP1 mRNA. To identify the direct binding of miR-186 with YAP1 mRNA, dual luciferase reporter assay was performed. The results demonstrated that miR-186 binds the 3'-UTR of YAP1 mRNA and regulates the expression of YAP1.

In conclusion, the present study demonstrated that miR-186 regulates the expression of YAP1 by direct targeting, inhibits PC cell proliferation, and exerts important biological functions in the occurrence and development of PC. Our study on the effect of miR-186 on PC provides theoretical evidence for the prediction, diagnosis and treatment of PC.

\section{Acknowledgements}

This work was supported by the Medical and Health Science and Technology Development Plan of Shandong Province (grant no. 2013WS0270).

\section{References}

1. Siegel RL, Miller KD and Jemal A: Cancer statistics, 2015. CA Cancer J Clin 65: 5-29, 2015.

2. Siegel R, Naishadham D and Jemal A: Cancer statistics, 2012. CA Cancer J Clin 62: 10-29, 2012.

3. Chen W, Zheng R, Zeng H and Zhang S: The updated incidences and mortalities of major cancers in China, 2011. Chin J Cancer 34: 502-507, 2015.

4. Tempero MA, Arnoletti JP, Behrman S, Ben-Josef E, Benson AB 3rd, Berlin JD, Cameron JL, Casper ES, Cohen SJ, Duff M, et al: Pancreatic adenocarcinoma. J Natl Compr Canc Netw 8: 972-1017, 2010.

5. Cho JH, Ryu JK, Song SY, Hwang JH, Lee DK, Woo SM, Joo YE, Jeong S, Lee SO, Park BK, et al: Prognostic Validity of the American Joint Committee on Cancer and the European Neuroendocrine Tumors Staging Classifications for Pancreatic Neuroendocrine Tumors: A retrospective nationwide multicenter study in South Korea. Pancreas 45: 941-946, 2016.

6. Arnachellum RP, Cariou M, Nousbaum JB, Jezequel J, Le Reste JY and Robaszkiewicz M: Pancreatic adenocarcinoma in the finistère area, france, between 2002 and 2011 (1002 cases): Population characteristics, treatment and survival. Pancreas 45: 953-960, 2016.

7. Le N, Sund M and Vinci A: Prognostic and predictive markers in pancreatic adenocarcinoma. Dig Liver Dis 48: 223-230, 2016.

8. Alsubai J, Matters GL, McGovern CO, Liao J, Gilius EL and Smith JP: Germline mutation of the CCK receptor: A novel biomarker for pancreas cancer. Clin Transl Gastroenterol 7: e134, 2015.

9. Liu L, Xu HX, Wang WQ, Wu CT, Xiang JF, Liu C, Long J, $\mathrm{Xu}$ J, Fu de L, Ni QX, et al: Serum CA125 is a novel predictive marker for pancreatic cancer metastasis and correlates with the metastasis-associated burden. Oncotarget 7: 5943-5956, 2016.

10. Kapoor A, Yao W, Ying H, Hua S, Liewen A, Wang Q, Zhong Y, Wu CJ, Sadanandam A, Hu B, et al: Yap1 activation enables bypass of oncogenic kras addiction in pancreatic cancer. Cell 158: 185-197, 2014.

11. Cebola I, Rodríguez-Seguí SA, Cho $\mathrm{CH}$, Bessa J, Rovira M, Luengo M, Chhatriwala M, Berry A, Ponsa-Cobas J, Maestro MA, et al: TEAD and YAP regulate the enhancer network of human embryonic pancreatic progenitors. Nat Cell Biol 17: 615-626, 2015.

12. Deng J, Lei W, Xiang X, Zhang L, Yu F, Chen J, Feng M and Xiong J: MicroRNA-506 inhibits gastric cancer proliferation and invasion by directly targeting Yapl. Tumour Biol 36: 6823-6831, 2015.

13. Jung KH, McCarthy RL, Chong Z, Uprety N, Barton MC and Beretta L: MicroRNA-194 regulates hepatocytic differentiation of progenitor cells by targeting YAP1. Stem Cells 34: 1284-1296, 2016. 
14. Livak KJ and Schmittgen TD: Analysis of relative gene expression data using real-time quantitative PCR and the 2(-Delta Delta C(T)) Method. Methods 25: 402-408, 2001.

15. Sudol M: Yes-associated protein (YAP65) is a proline-rich phosphoprotein that binds to the SH3 domain of the Yes proto-oncogene product. Oncogene 9: 2145-2152, 1994.

16. Liu AM, Zhi X and Luk JM: An update on targeting Hippo-YAP signaling in liver cancer. Expert Opin Ther Targets 16: 243-247, 2012.

17. Harvey KF, Xiaomeng $Z$ and Thomas DM: The Hippo pathway and human cancer. Nat Rev Cancer 13: 246-257, 2013.

18. Randy $\mathrm{J}$ and Georg H: The two faces of Hippo: Targeting the Hippo pathway for regenerative medicine and cancer treatment. Nat Rev Drug Discov 13: 63-79, 2014

19. Jeong W, Kim SB, Sohn BH, Park YY, Park ES, Kim SC Kim SS, Johnson RL, Birrer M, Bowtell DS, et al: Activation of YAP1 is associated with poor prognosis and response to taxanes in ovarian cancer. Anticancer Res 34: 811-817, 2014.

20. Xia Y, Zhang YL, Yu C, Chang T and Fan HY: YAP/TEAD co-activator regulated pluripotency and chemoresistance in ovarian cancer initiated cells. PLoS One 9: e109575, 2014.

21. Tsujiura M, Mazack V, Sudol M, Kaspar HG, Nash J, Carey DJ and Gogoi R: Yes-associated protein (YAP) modulates oncogenic features and radiation sensitivity in endometrial cancer. PLoS One 9: e100974, 2014.

22. Touil Y, Igoudjil W, Corvaisier M, Dessein AF, Vandomme J, Monté D, Stechly L, Skrypek N, Langlois C, Grard G, et al: Colon cancer cells escape 5FU chemotherapy-induced cell death by entering stemness and quiescence associated with the c-Yes/YAP axis. Clin Cancer Res 20: 837-846, 2013.
23. Kim SK, Jung WH and Koo JS: Yes-associated protein (YAP) is differentially expressed in tumor and stroma according to the molecular subtype of breast cancer. Int J Clin Exp Pathol 7: 3224-3234, 2014

24. Jerhammar F, Johansson AC, Ceder R, Welander J, Jansson A, Grafström RC, Söderkvist P and Roberg K: YAP1 is a potential biomarker for cetuximab resistance in head and neck cancer. Oral Oncol 50: 832-839, 2014.

25. Zhao X, Mohan R, Özcan S and Tang X: MicroRNA-30d induces insulin transcription factor MafA and insulin production by targeting mitogen-activated protein 4 kinase 4 (MAP4K4) in pancreatic $\beta$-cells. J Biol Chem 287: 31155-31164, 2012.

26. Zhang ZL, Bai ZH, Wang XB, Bai L, Miao F and Pei HH: miR-186 and 326 predict the prognosis of pancreatic ductal adenocarcinoma and affect the proliferation and migration of cancer cells. PLoS One 10: e0118814, 2015.

27. Lee YH, Kim SY and Bae YS: Upregulation of miR-760 and miR-186 is associated with replicative senescence in human lung fibroblast cells. Mol Cells 37: 620-627, 2014.

28. Sun P, Hu JW, Xiong WJ and Mi J: miR-186 regulates glycolysis through Glut1 during the formation of cancer-associated fibroblasts. Asian Pac J Cancer Prev 15: 4245-4250, 2014.

29. Cui G, Cui M, Li Y, Liang Y, Li W, Guo H and Zhao S: MiR-186 targets ROCK1 to suppress the growth and metastasis of NSCLC cells. Tumour Biol 35: 8933-8937, 2014. 